\title{
Integration of Knowledge Creation and Quality Management Practices in the UAE Hospitality sector
}

\author{
[Malini Nair, Sanoop George]
}

\begin{abstract}
This research study aims to link the study of Knowledge Creation through Quality Management Practices by using one of the four hypotheses proposed by Linderman, Schroeder, Zaheer, Liedtke, Choo 's model and validating the model by its application to the UAE hospitality sector. The purpose of this paper is to emphasize the achievement of organizational excellence due to the augmented integration of quality management practices viz continual improvement practices with knowledge creation.
\end{abstract}

Several quality thought leaders have considered the role of knowledge in quality management practices. For example, Deming proposed The Deming System of Profound Knowledge ${ }^{\mathrm{TM}}$ that dealt explicitly with knowledge. However, various authors in the quality field diverge considerably when contemplating knowledge. Therefore, they propose an integrated view of quality and knowledge using Nonaka's theory of knowledge creation. This integrated view helps illuminate how quality practices can lead to knowledge creation and retention. (Liederman, 2004)

\section{Introduction}

The research discusses knowledge management and its applicability in the UAE Hospitality industry as an exemplification of an intensive knowledge based industry. The UAE workforce is distinctive given that it is diverse in culture and nationality. This has both pros and cons when the knowledge comes from a variety of resources but sharing and reluctance in employee participation to provide creative and innovative ideas takes it a step behind. The UAE government however is very proactive and encourages innovation in these sectors to a great extent. There are some excellence awards in place which promotes the use of continual improvement practices in the hospitality industry.

With the UAE's vision of creating a knowledge based society knowledge management is an area of clear focus, so as to improve innovation and delivery of their services. This research attempts to apply the existing model of knowledge and its enablers in the UAE hospitality industry through an interview method addressed to managers in the hospitality sector to understand the use and promotion of knowledge management and its link to the Total Quality Management practices in terms of value proposition.

\section{A. Hospitality Industry in the UAE - External Analysis}

Political Factors

Each of the 7 Emirates themselves have individual governmental organizations, allowing for flexible management across the country. On the negative side, the United Arab Emirates occasionally has political conflicts with nearby countries about the ownership of oil reserves or land. The UAE has healthy trade relations with many countries across the globe.[1]

\section{Economical Factors}

The UAE's thriving hospitality industry, enjoying an impressive track record for its consistently high occupancy rates and sustained capacity expansion drive, is set for a new phase of exponential growth that is expected to catapult the Emirates to the ranks of the world's most sought-after destinations for international visitors by 2020, when Dubai will be hosting the World Expo.

\section{Social Factors}

As per Dubai Airport SP 2020, two thirds of the worldwide populace lives within eight hours flight from Dubai and one third within four hours making it a reachable and befitting travel route making UAE a central location. The baby boomer generation also likes to travel more than in the past due to excellent travel packages being offered by the travel industry.

\section{Technological Factors:}

When we talk about the transformative effect of technology, in the Middle East - and especially in the UAE and Dubai - that has to include Smart Hospitality. With Smart Tourism a Dubai Smart City pillar, and 25 million visitors expected for World Expo 2020, hotels also need to find a competitive differentiator. 


\section{B. Total Quality Management}

The key components of TQM are customer focus, continuous improvement in products, processes and services, statistical measurement, benchmarking, as well as the employee empowerment.[10]TQM requires Knowledge Management in the organizations.

This study uses a descriptive approach to report on a recent exploratory investigation of the current knowledge management uses and related strategic challenges in hotels located in the United Arab Emirates (UAE). More specifically, we attempt to: (1) analyze and report findings of a survey on knowledge management and related challenges in four- and five-star hotels in the UAE, (2) assess the degree to which these hotels are using KM strategically to integrate and improve processes and customer service with special focus on $\mathrm{TQM}$, and (3) explore opportunities for more effective strategic management of KM in four- and five-star hotels in this region and elsewhere.

\section{Methodology}

To collect the data we conducted a questionnaire survey that was emailed to 50 randomly selected four- and five-star hotels in the UAE. These represent the vast majority of luxury hotels in the UAE as most of them are chains. Only 34 surveys were found to be usable for analysis. As Table 1 shows, the hotels included in this study are located in the five major UAE cities/emirate.

Table 1.Hotel locations in the UAE.

\begin{tabular}{|l|r|r|r|}
\hline $\begin{array}{l}\text { Emirate } \\
\text { Abu }\end{array}$ & \multicolumn{1}{|l}{ 5-Star } & \multicolumn{1}{l|}{ 4-Star } & \multicolumn{1}{l}{ Total } \\
Dhabi & $42(29 \%)$ & $34(41 \%)$ & $76(33 \%)$ \\
\hline Ajman & $4(3 \%)$ & $4(5 \%)$ & $8(3 \%)$ \\
\hline Al Ain & $2(1 \%)$ & $5(6 \%)$ & $7(3 \%)$ \\
\hline Dubai & $92(63 \%)$ & $26(32 \%)$ & $118(52 \%)$ \\
\hline Sharjah & $7(5 \%)$ & $13(16 \%)$ & $20(9 \%)$ \\
\hline Total & $147(100 \%)$ & $82(100 \%)$ & $229(100 \%)$ \\
\hline
\end{tabular}

The surveys were administered directly to the most senior executive in each hotel. In an attempt to avoid some of the potential disadvantages inherent(key informant)[16] in the technique of data collection, the respondents were given the option and, in fact, encouraged to refer the questions to any of their managers as they deem necessary. This is because we understood that some managers might not be responsible for certain quality practices used at the department level for innovations. Moreover, the respondents were assured that the information they provided would be kept confidential and would only be used for general analysis without mentioning any hotel name.

Total quality management was where five-star hotels hired more consultants than the four-star hotels. However, four-star hotels seemed to be making a significant effort by sending employees to workshops and conferences (80\%) than the fivestar ones. In contrast, with respect to customer resource management, a lesser percentage of the four-star hotels reported that they hired consultants compared to those of the five-star hotels. However, both types of hotels reported a relatively high level of involvement workshops and conference participation for employees. At the same time, the five-star hotels seemed to be investing much more in knowledge acquisition than four-star hotels.

This study also tries to shed some light on the current state of Knowledge Management in UAE hotels and validating the Linderman model. In an effort to develop insights for hoteliers and researchers alike, we explored the pertinent signs of using $\mathrm{KM}$ strategically to achieve a competitive advantage. The data collected on the interrelated practices of TQM, shows how Knowledge Creation initiatives can help in organizational performance as well. TQM tools and systems in four-star and five-star hotels were implemented in quite similar ways and levels. Several four- and five-star hotels were implementing tools such as hazard analysis and critical control points (HACCP), benchmarking, and employee empowerment. Although difficult to tally, five-star hotels seemed to be using a larger number of tools and practices. The data also showed that TQM was managed by different managers in different departments. In some hotels, TQM was under the responsibility of the general manager, while in others it was managed by the HR or food and beverage or operations manager.

Table 2 : Nonaka 's Knowledge Creation Model

\begin{tabular}{|l||l|l|}
\hline \multicolumn{2}{|c|}{ To } \\
\hline
\end{tabular}

Table 2: We used the exploratory study to illustrate the value knowledge management gives to solve some of the strategic 
challenges managers face in the hotel industry. Drawing on the literature review and the results of this exploratory study, we validated the $\mathrm{H} 2$ Hypotheses (continual improvements) outlined in the Linderman model and capture relationships. Quality improvement and TQM have also benefited from organizational learning [5] and knowledge management initiatives [2]

This study raises an important question about the readiness of UAE hotels and similar ones for knowledge-based competition, though we recognize that several hotels around the world have shown pioneering attitudes of acting as lead users of KM, organizational innovations, and best practices.

In identifying $\mathrm{KM}$ practices as antecedents to organizational performance, we attempted to include factors (e.g., knowledge processing behaviors, management practices, and organization culture) that are similar to those identified by [9] and others, yet maintain clarity regarding our research question. Our objective was to address the KM issue directly.

According to [6], $\mathrm{KM}$ is focused on processes and mechanisms for locating and sharing what is known by an organization or its external stakeholders. The ability to share internal best practices is important to overall organizational performance [13], and exploiting external knowledge is crucial in driving new product innovation [14] [12]. To this end, we included items to measure the extent to which the organization is able to identify internal sources of expertise, culture is perhaps the most influential factor in promoting or inhibiting the practice of KM. [7]

Specifically, organizations that value their employees for what they know, and reward employees for sharing that knowledge create a climate that is more conducive to KM. We therefore, included items to measure these aspects of organizational culture:-Deming's Worksheet. In total, we identified $14 \mathrm{KM}$ practices, each having been suggested elsewhere as being important for effective KM. We used a five-point Likert-type scale to ascertain the extent to which an organization was actively engaged in each of these KM practices. A score of less than $75 \%$ would mean the organization needs improvement in terms of continual improvement. This formed the basis for questions asked to the managers which gave us data about how they manage knowledge vis a vis continual improvement.

\section{Findings:}

One of the major factors that is having indirect influence is the economic factors within a region or around the globe. A slight fluctuation in the economy can make people spend less or more in the hospitality industry. Tourism and hospitality will perform poor when the global economy is declining.

Any changes in the law and order also will affect the tourism and hospitality industry. As any regulations imposed by the government changes occasionally it can have no control by the hospitality industry. Changes in taxes and increase in price of items are also coming under these factors which can affect the hospitality industry.

The data revealed new recruiting strategies, offering more knowledge-intensive training programs, re-engineering of key processes to take advantage of the boom in the market and adopting a formally planned differentiation strategy based on web-based Customer Relationship Management and Supply Chain Management to optimize the customers' experience. However, this would start with a full assessment of business goals and supporting initiatives, an endeavor that may seem costly to hoteliers and may require more knowledge creation but would eventually lead to organizational excellence through quality. [3]

Introduction of new technologies also affect certain companies in hospitality. If new technology which comes though policies of innovation (continuous improvement) is not being adopted by companies competitors will take over and it will be difficult to sustain. One of the areas that is of growing concern in technology field is the adoption of different software which are used to control the tour and hotel booking facilities. [1]

\section{Limitations:}

When addressing managerial issues related to service quality and knowledge management, empirical studies in tourism and hospitality have often focused on a specific region, currently there is a gap of empirical evidence in the UAE with respect to Knowledge Creation and Organizational Excellence which we plan to explore in our next research paper. Our data was collected randomly based on convenience sampling.

\section{Conclusions.}

There was a noteworthy relationship between Knowledge management practices of Externalization (conversion of Tacit to Explicit) and Internalization (conversion of Explicit to Tacit) to Continuous Improvement .This meant that the understanding of the tacit knowledge was not well developed limiting the benefits of the conversion process of tacit into organizational knowledge. Similar findings were also reported by [3] regarding the absence of knowledge sharing and socialization to convert due to cultural issues within the workforce. Management support, communication of constructive goals, sharing culture, and interdepartmental communication is a must for continual improvement in these sectors [15]

However, is there a particular path or a sequence of steps that hotels in our sample must follow before managing knowledge considering the pace at which this sector is growing? Are these hotels advanced enough along that path to use knowledge-based TQM? Perhaps the answer is more basic steps should precede these initiatives. Such steps might include more systematic planning and learning from other 
Proc. of the Fifth International Conference on Advances in Social Science, Management and Human Behaviour - SMHB 2017. Copyright (C) Institute of Research Engineers and Doctors. All rights reserved.

ISBN: 978-1-63248-124-5 doi: 10.15224/ 978-1-63248-124-5-41

industries such as manufacturing and retail industries in the region. At the international level benchmarking is an aspect that should be looked into for hotels to learn the process of creation and management of knowledge where the culture has not been found conducive.

\section{References}

\section{[1] (2016, January 8). External Factors Affecting Tourism} Industry. Westford School of Management.

[2]A.S. Mukherjee, M. L. (1998). Knowledge driven quality improvement. Management Science, S35-S49.

[3]AbdelKadher Daghfous, B. R. (2009). The strategic management of information technology in UAE hotels: An exploratory study of TQM, SCM, and CRM implementations. Technovation, 29(9), 588595.

[4]Bush, T. (2016, June 10). Retrieved from http://pestleanalysis.com: http://pestleanalysis.com/pestle-analysis-of-uae/

[5]C.H.Fine. (1986). Quality improvement and learning in productive systems. Management Science, 13011315 .

[6]Davenport, T. a. (1998). Working knowledge: How Organisations Manage What They Know. Harvard Business School Press.

[7]Davenport, T. D. (1998). Successful Knowledge Management Projects. Sloan Management Review, 43-57.
[8]G. Hult, D. K. (2005). Knowledge as a strategic resource in supply chains. Journal of Operations Management, (2005), pp. 458-475, 458-475.

[9]Gold, A. A. (2001). Knowledge management: An organizational capabilities perspective. Journal of Management Information Systems, 18(1), 185-214.

[10]J.Ross. (1993). In Total Quality Management Texts, Cases and Readings. Delray Beach: St.Lucie Press.

[11]Liederman, S. (2004, Dec). Integrating quality management practices with knowledge creation processes. Journal of Operations Management, 22(6).

[12]Sher, P. a. (2004). Information technology as a facilitator for enhancing dynamic capabilities through. Information and Management, 933-945.

[13]Szulanski, G. (1996). Exploring Internal Stickiness: Impediments to The Transfer of Best Practice Within The Firm. . Strategic Management Journal, 27-44.

[14]von Hippel, E. (1994). "Sticky Information"and the Locus of Problem Solving: Implications for Innovation. Management. Management Science, 429 - 439.

15]Yichen, Lin. 2006. 'A knowledge-enabled procedure for customer relationship management": Industrial Marketing Management, 446-456.

[16]Phillips, W. Lynn. 'Assessing Measurement Error in Key Informant Reports': Journal of Marketing Research, Vol. 18, No. 4 (Nov., 1981), pp. 395-415 